\title{
Puzzling functions of HSV-1 miRNAs in productive and latent infection
}

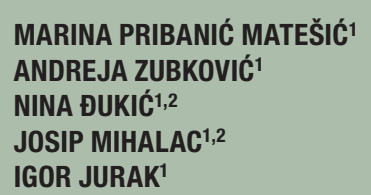

${ }^{1}$ Laboratory for Molecular Virology, Department of Biotechnology, University of Rijeka, Rijeka, Croatia

${ }^{2}$ Master program Biotechnology in Medicine, Department of Biotechnology, University of Rijeka, Rijeka, Croatia

\section{Corresponding author:}

Igor Jurak

E-mail: igor.jurak@biotech.uniri.hr

Keywords: herpes simplex virus; miRNA; gene regulation; Iytic-latent switch

\begin{tabular}{|c|c|}
\hline Abbreviat & ions: \\
\hline ADAR & - adenosine deaminase acting on RNA \\
\hline ATG16L1 & - Autophagy Related 16 Like 1 \\
\hline ATRX & $\begin{array}{l}\text { - alpha thalassemia/mental retardation } \\
\text { syndrome X-linked }\end{array}$ \\
\hline CDKNA2 & - cyclin-dependent kinase inhibitor 2A \\
\hline DDX41 & - (DEAD)-box helicase 41 \\
\hline DGCR8 & - DiGeorge syndrome critical region 8 \\
\hline DRG & - dorsal root ganglia \\
\hline E (protein) & - early protein \\
\hline & - glycosylphosphatidylinositol \\
\hline HITS-CLIP & $\begin{array}{l}\text { - high-throughput sequencing of RNA } \\
\text { isolated by crosslinking } \\
\text { immunoprecipitation }\end{array}$ \\
\hline ICP & - infected cell polypeptide \\
\hline IE (protein) & - immediate early protein \\
\hline IFN- $\gamma$ & - interferon gamma \\
\hline KLHL24 & - Kelch-like 24 \\
\hline L (protein) & - late protein \\
\hline LAT & - latency-associated transcript \\
\hline LIFR & $\begin{array}{l}\text { - leukemia inhibitory factor receptor } \\
\text { alpha }\end{array}$ \\
\hline miRNA & - microRNA \\
\hline PAR-CLIP & $\begin{array}{l}\text { - photoactivatable ribonucleoside- } \\
\text { enhanced crosslinking and } \\
\text { immunoprecipitation }\end{array}$ \\
\hline PIGT & $\begin{array}{l}\text { - phosphatidylinositol glycan anchor } \\
\text { biosynthesis class T }\end{array}$ \\
\hline RISC & - RNA-induced silencing complex \\
\hline SORT1 & - sortilin 1 \\
\hline
\end{tabular}

\section{Abstract}

Herpes simplex virus (HSV) is a widespread human pathogen able to cause a broad spectrum of diseases of varying severity. HSV-1, and closely related virus HSV-2, employ a number of functions to evade host defense mechanisms and tailor the cellular environment during their complex life cycle comprised of productive and life-long latent infection. Once the latency is established, the virus can periodically reactivate in response to different stimuli and cause recurrent disease. Despite being one of the most intensively studied viruses, many biological aspects involved in the control of the lytic-latent switch and regulation of viral and host gene expression remained unclear. Discovery of the HSV-encoded microRNAs (miRNAs), a class of small regulatory RNAs, led to the hypothesis that they could have a central role in the establishment and maintenance of latency. HSV-1 and HSV-2 encode many miRNAs, differentially expressed during both phases of infection. The functions of HSV-encoded miRNAs have been experimentally addressed by several laboratories; however, the exact roles remain inconclusive. In this review, we will discuss the function of HSV-encoded miRNAs described to date, in terms of their viral and host targets, and the potential significance of such regulation for viral infection.

\section{INTRODUCTION}

\section{Herpes simplex virus 1}

Werpes simplex virus 1 (HSV-1) is an important human pathogen 1 commonly known as the causative agent of cold sores. It is one of the most intensively studied viruses and widely used model to study a myriad of cellular processes including antivirals, and also a vector in cancer therapy. Alike all members of the herpesvirus family, HSV-1 replication is characterized by two distinct phases of infection, the productive and latent phase (1). Following oropharyngeal infection of epithelial cells, the virus initiates productive (lytic) phase of infection characterized by an abundant but tightly controlled cascade of gene

$\begin{array}{ll}\text { TGFBR1 } & \text { - transforming growth factor beta receptor } 1 \\ \text { Ubr1 } & \text { - ubiquitin protein ligase E3 component n-recognin } \\ \text { UL30 } & \text { - unique long } 30 \\ \text { wt } & \text { - wild type } \\ \text { XP05 } & \text { - exportin } 5\end{array}$

Received May 29, 2020

Revised July 10, 2020

Accepted July 10, 2020 
expression. The immediate early proteins (IE), largely represented by transcriptional factors and inhibitors of innate immunity, are expressed first, followed by the expression of early (E) proteins. Early proteins are non-structural proteins necessary for the replication of viral DNA (e.g. thymidine kinase, UL30 DNA polymerase, etc.). The onset of DNA replication is followed by the expression of late (L) genes, many of which are structural proteins. Formed nucleocapsids go through a complex maturation and envelopment processes before virions leave the cell and spread. Productive infection is followed by the entry of the virus into sensory neurons innervating the site of primary infection in which the virus will establish a life-long latent infection (latency). In contrast to rapid and massive gene expression and virus spread during productive infection, in latency viral genes are largely suppressed, and no viral progeny is formed. During the latent infection, only the latency-associated transcripts (LATs), which give rise to several microRNAs (miRNAs) and long non-coding RNA (lncRNA) in the form of a very stable LAT intron, are abundantly expressed (2). Yet, the exact functions of virusencoded miRNAs are rather puzzling and will be discussed in detail below. On the other hand, the LAT intron has been discovered more than 40 years ago and many diverse functions have been attributed to it (3), including suppression of IE gene expression, inhibition of apoptosis, functions in heterochromatin formation on virus genome, neuronal cell tropism and immunity (4-8). Importantly, under different stimuli, such as stress, fever, or various environmental factors, the latent virus can reactivate and move along the axons, usually to sites where the primary infection was initiated, and cause recurrent disease. Most of the above-mentioned biological properties of HSV-1 are shared by the evolutionary closely related virus, herpes simplex virus 2 (HSV-2). Although HSV-1 and HSV-2 share overall more than $80 \%$ homology (9), HSV-2 occupies different niche and it is traditionally known as the causative agent of genital herpes. Important to note, the number of genital HSV-1 infections is increasing in developed countries, which can be associated with delayed acquisition of primary oral infections and increased frequency of neonatal infections (10-12). Following genital infection, both HSV-1 and HSV-2 establish latency typically in lumbosacral dorsal root ganglia (DRG), i.e. ganglia proximal to the primary site of the infection, however, the efficiency of reactivation between these two viruses differs markedly (13). Interestingly, it has been shown in a murine model that HSV-1 and HSV-2 establish latency in different populations of ganglionic neurons, and these properties have been linked to the LATs (14), but the exact molecular mechanism of this neuronal tropism has not been revealed yet. The latency is clinically the most relevant phase of HSV-1 and HSV-2 infection, yet, due to the extreme biological complexity of these viruses and countless technical challenges, the exact molecular mechanisms governing the establishment, maintenance, and reactivation from the latency are poorly understood. Nonetheless, one can predict that, with the dawn of the massive parallel analyses (sequencing and mass-spectrometry) and establishment of in vitro latency models, we can expect breakthroughs in the field rather soon.

\section{miRNAs}

miRNAs are small $(-22 \mathrm{nt})$ regulatory RNAs that adjust the expression of genes in plants, animals, and viruses (15). miRNAs arise from hairpin-containing precursor transcripts (pri-miRNAs) that are sequentially processed by two RNAse III complexes, the nuclear Drosha/DGCR8 (DiGeorge syndrome critical region 8) complex releasing a typical hairpin structure (pre-miRNA), and the cytoplasmic Dicer/TRBP complex that generates miRNA duplex carrying a 2 nucleotide 3 'overhangs. The miRNA duplex is then loaded into Argonaute and one of the strands of the duplex will represent the mature miR$\mathrm{NA}$, whereas the other strand (usually called star strand) will be released and degraded (reviewed in (15)). The mature miRNA will guide the silencing complex to pair with partially complementary sites within target mRNAs and utilize posttranscriptional repression. The part of miRNA, designated as a seed sequence (nucleotide $2-8$ ), has a pivotal role in recognition of the target sites, which are usually found within 3' untranslated regions (3' UTRs) of mRNAs $(16,17)$. Interestingly, although miRNAs have evolved from the ancestral antiviral RNA silencing pathway (18), many viruses implement miRNAs to achieve an efficient replication by, on the one hand, encoding miRNAs (e.g. herpesviruses, baculoviruses, polyomaviruses, retroviruses, etc.) or, on the other hand, using host miRNAs (e.g. hepatitis $\mathrm{C}$ virus requires direct binding of miR122 to initiate replication) (19). From the virus life cycle perspective, miRNAs as regulatory molecules have many advantages over proteins, including a capacity to regulate a large number of genes, non-immunogenicity, and rapid evolution (i.e. one nucleotide change within the seed region can dramatically change the targetome of a miRNA) (20). This is particularly relevant for the viruses that establish latency in neuronal cells, such as HSV-1 and HSV2 , which will be discussed in greater detail below.

\section{The biogenesis, expression and sequence of HSV-1 miRNAs}

HSV-1 has a very complex transcriptional pattern and many transcripts have not been properly annotated yet (21-23). Indeed, for the vast majority of HSV-1 encoded miRNAs, the precursors (pri-miRNAs) have not been experimentally validated or identified, nonetheless it is thought that they arise through the canonical biogenesis pathway. The majority of miRNAs abundantly expressed in latently infected human trigeminal ganglia (24) and latency models (25), miR-H2 - miR-H8, strongly depend on the LAT promoter (26), indicating that LATs are their precursors. The only exception is miR-H6 that is likely expressed from the LAT promoter but in the opposite 
direction and from the transcript that has not been described yet (26). At the same locus, but antisense to miRH6 (i.e. sense to LATs), another miRNA, miR-H1, is expressed and abundantly detected in productive infection, but absent in latency. miR-H1 likely arises from the $0.7 \mathrm{~kb}$ transcript encoded just upstream of the LAT promoter ((23), Matesic et al., unpublished data), previously found to be expressed only by more virulent laboratory HSV-1 strains, McKrae and 17 (27). The origin of other 12 miRNA hairpins is far less defined; however, the recent sequencing efforts have identified several unknown transcripts running through the miRNA loci that might be precursors of these miRNAs (23). Interestingly, characteristic to many virus-encoded miRNAs, but fairly rare in animals, HSV-1 miRNAs do not show a strong strandbias, or in other words, many miRNA duplexes result in a relatively similar abundance of miRNAs derived from both strands (i.e. no exact star strand) ((25), Zubkovic et al., unpublished). Although this phenomenon can be rationalized from the perspective of maximizing the coding potential, the exact molecular mechanism is unknown. Another peculiarity of HSV-1 miRNAs is a relatively high number of isomiRs, i.e. miRNAs with nucleotide variations at ' 5 ' and '3' end, which might also increase the number of potential targets, however, this phenomenon has not been addressed comprehensively (25). One possibility is that such sloppy processing and unbiased selection of strands are internal properties of pre-miRNAs and duplexes (i.e. energetically equivalent in association with Ago), and/or another possibility is that virus actively modulates the biogenesis process. Indeed, recently Pan et al. have shown that HSV-1 infection blocks miRNA biogenesis at the stage of nuclear export of pre-miRNAs, the process that depends on the expression of ICP27 (Figure 1), an important virus IE protein (28). Furthermore, we and others have recently found evidence that specific virus miRNAs can be posttranscriptionally edited by adenosine deaminase acting on RNA (ADAR) (29). Such editing of miRNA precursors (i.e. changing adenosine to inosine) within the seed region of miRNA can additionally broaden the spectrum of miRNA targeting, giving additional advantages to the virus. Nonetheless, further investigation of the basic biology of HSV-1 miRNAs is needed to better understand these processes. Important to mention, additional complexity added to the HSV-1 biological processes was reported by Roizman's laboratory, discovering that HSV-1 miRNAs, together with some host factors, are packed into small vesicles released by infected cells (i.e. exosomes) (30). HSV-1 miR-H28 and miR-H29, two HSV-1 miRNAs expressed late in the infectious cycle and transferred to recipient cells, restrict the transmission of the virus from infected to uninfected cells by inducing the synthesis of gamma interferon (IFN- $\gamma$ ) (30-32). The results support the growing body of evidence indicating that HSV-1 encodes several miRNAs that limit its spread (e.g. miR-H2, $-\mathrm{H} 3$ and $-\mathrm{H} 4$, described below), possibly by promoting the establishment of latency.

\section{Functions of HSV-1 miRNAs - viral targets}

Despite major progress and development of techniques for miRNA functional studies (PAR/HITS-CLIP (photoactivatable ribonucleoside-enhanced crosslinking and immunoprecipitation / high-throughput sequencing of RNA isolated by crosslinking immunoprecipitation), bioinformatics predictions, etc.) (33), there is still limited knowledge about HSV-1 miRNAs in the productive, and particularly, latent infection. The HSV field, in contrast to gammaherpesviruses, lacks a broadly accepted latency model in vitro (in cultured cells) that would enable various experimental approaches. Nonetheless, functions of some miRNAs are strongly indicated by their genomic location, i.e. encoded antisense to important virus genes. For example, miR-H2, $-\mathrm{H} 7$, and - $\mathrm{H} 8$ are encoded antisense to the gene encoding ICP0, an important transactivating IE protein. Similarly, miR-H3 and -H4 are encoded antisense to ICP34.5, the main neurovirulence factor. Although it has been shown that miR-H2 can regulate ICP0 transcript in co-transfection assays $(34,35)$ and has been associated with ICP0 in a PAR-CLIP analysis (36), the mutation of miR-H2 did not lead to a significant increase in the expression of ICP0 in productively infected cells in vitro, or during acute virus infection in mice, nor to any other obvious phenotype in HSV-1 strain KOS (34). On the other hand, Jiang et al. have investigated similar mutations in more virulent HSV-1 strain McKrae and have observed somewhat increased expression of ICP0 and a significant increase in neurovirulence (37). The discrepancies between these two studies can be explained by the use of different models, but can also support the notion that the function of miRNAs is rather a fine-tuning of gene expression and biological processes, which is difficult to quantify. Indeed, an investigation of homologous miRNAs in HSV-2 also did not show a significant phenotype in the guinea pig model (38). Of note, Pan et al. have shown that, in fact, a neuron-specific host miRNA, miR138, targets ICP0 and promotes establishment of latency (39). Other HSV-1 miRNAs do not have obvious targets, however, some roles in regulating virus or host genes have been proposed or investigated. For example, miR-H6 shows a certain level of complementarity to the transcript encoding ICP4, an essential IE transcriptional factor, however, the biological relevance of this interaction is not clear (35). It has been shown that the wt virus replicated less efficiently in the cells transfected with miR-H6 prior to the infection and that the expression of ICP4 is significantly affected. However, in these cells, many important host factors were found to be downregulated, including IL-6, and thus it is not clear is this the direct effect of miR-H6 on ICP4, or an indirect effect of less permissive conditions in transfected cells (40). Recently, Barrozo et al. have investigated virus with deletion of the entire miRH1/H6 locus and have observed a severe reduction in reactivation of HSV-1 in mouse and rabbits models (41), 
which is in accordance with previous observations of phenotypes in mutants with large deletions of the loci upstream od the LAT promoter $(42,43)$. However, the molecular mechanism is still unknown, and, at this point, it is not possible to link the function to either miR-H1 or -H6. On the other hand, since miR-H1 and miR-H6 are encoded at the same locus but on different DNA strands (i.e. antisense to each other), these two miRNAs may regulate the expression of each other. Such functional miRNA antagonism is rather rare in nature; however, it has been observed in eukaryotes (44). HSV-1 encodes 5 such potentially antagonistic miRNA pairs including the above-mentioned - $\mathrm{H1}$ and - H6, as well as the - H11 (palindromic sequence), - $\mathrm{H} 2$ and $-\mathrm{H} 14,-\mathrm{H} 7$ and - $\mathrm{H} 27,-\mathrm{H} 12$ and -H13 (25), however, the biological relevance of this is unknown. Interestingly, HSV-2 encodes homologs of most of HSV-1 miRNAs, but it does not encode a homolog of miR-H1 (25), indicating that miR-H1 might be a molecular determinant of biological differences between these two closely related viruses.

\section{Functions of HSV-1 miRNAs - host targets}

Virus miRNAs, in addition to viral targets, can also regulate host genes, and a number of targets have been identified for different HSV-1 miRNAs (briefly summarized below in Figure 1). Although the biological relevance of these regulations has not been verified or investigated in relevant models in vivo, some potential targets involved in various cellular processes, including apoptosis, cellcycle control, cell-signaling and immunity, are briefly listed below (Figure 1). For example, HSV-1 miR-H1 and HSV-2 miR-6, two miRNAs that share the seed sequence, have been shown to downregulate alpha-thalassemia/mental retardation syndrome X-linked (ATRX), an effector of intrinsic immunity, in transient transfection experiments. However, downregulation of ATRX protein has also been noted in cells infected with wt virus and a mutant virus lacking miR-H1 and -H6, thus indicating other mechanisms, in addition to mentioned miRNAs that contribute

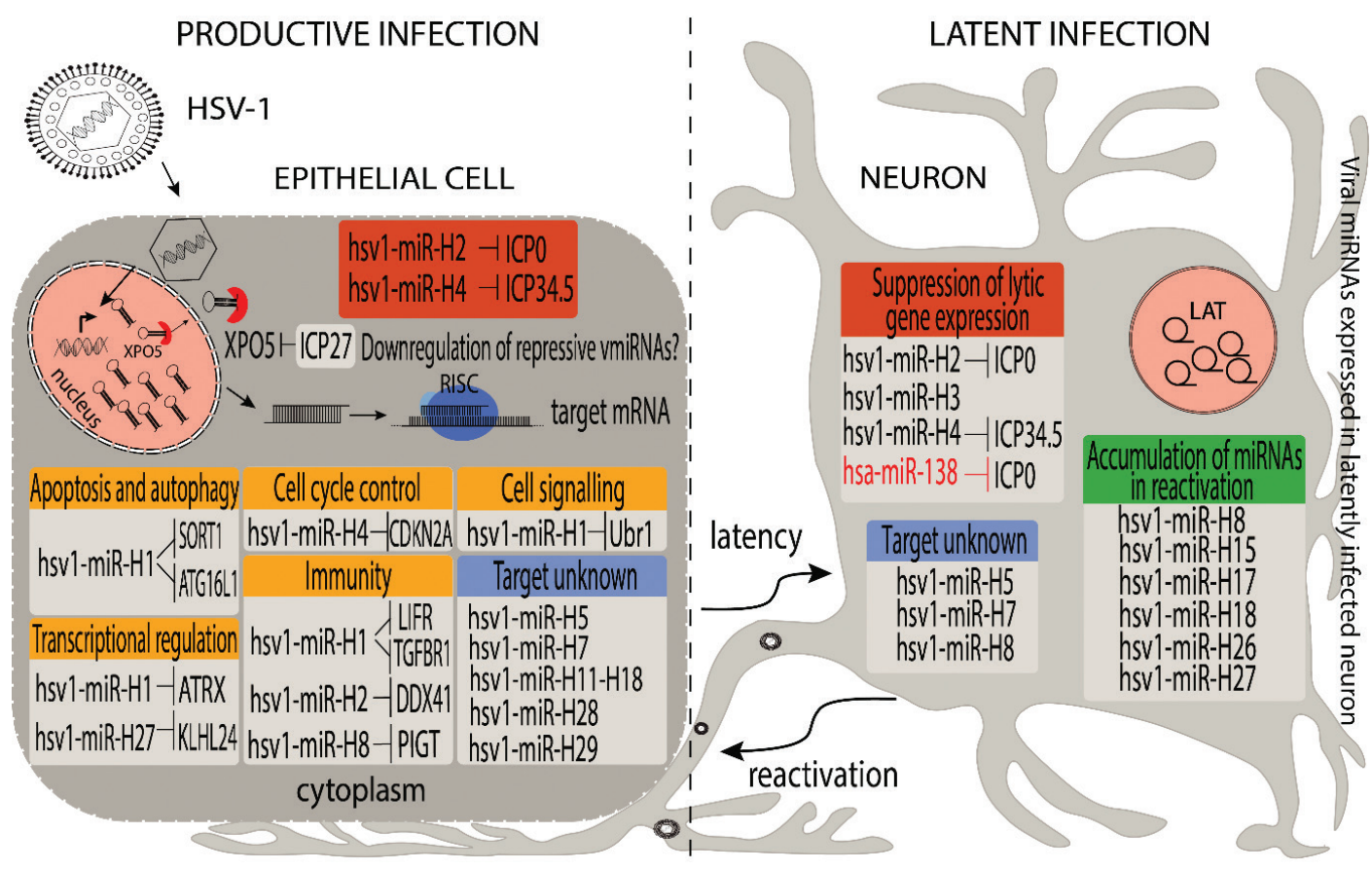

Figure 1. Viral and host targets of HSV-1 miRNAs in productive and latent infection. HSV-1 expresses many miRNAs by which it modifies the expression of viral and host genes. During the productive infection, a number of HSV-1 miRNAs have been shown to interfere with different host genes involved in apoptosis, cell cycle control, cell signaling, transcriptional regulation and immunity, depicted in orange titled boxes. During both stages of infection miR-H2 and-H4 regulate important viral proteins, transcriptional activator ICPO and neurovirulence factor ICP34.5, respectively, as depicted in brown box. Viral protein ICP27 is involved in downregulation of XPO5, thus inhibiting the nuclear export of pre-miRNAs late in infection. After productive infection, HSV-1 migrates to sensory neurons where latent infection is established and from where it can be periodically reactivated. In latent phase, host miRNA, miR-138 (marked with red letters) regulates viral protein $I C P O$, alongside miR-H2 and-H4 (brown-titled box). Several miRNAs were found to be accumulated during reactivation (green-titled box). miRNAs detected in both phases, whose targets are unknown, are depicted in blue-titled boxes. LAT - latency associated transcript, ICPO infected cell polypeptide 0, ICP34.5 - infected cell polypeptide 34.5, ICP27 - infected cell polypeptide 27, XPO5 - Exportin-5, RISC - RNA induced silencing complex, LIFR - Leukemia Inhibitory Factor Receptor Alpha, TGFBR1 - Transforming Growth Factor Beta Receptor 1, ATG16L1 - Autophagy Related 16 like 1, SORT1 - Sortilin 1, CDKNA2 - cyclin-dependent kinase inhibitor 2A, Ubr1 - ubiquitin-protein ligase E3 component n-recognin 1, ATRX - alpha-thalassemialmental retardation syndrome X-linked, KLHL24 - Kelch like family member 24, DDX41-(DEAD)-box Helicase 41, PIGT-phosphatidylinositol glycan anchor biosynthesis class T. 
to the regulation of ATRX (45). The function of miR-H1 has been thoroughly studied and its potential to regulate a number of host genes has been shown, including Leukemia Inhibitory Factor Receptor Alpha (LIFR), Transforming Growth Factor Beta Receptor 1 (TGFBR1), Autophagy Related 16 like 1 (ATG16L1), Sortilin 1 (SORT1), ubiquitin protein ligase $\mathrm{E} 3$ component n-recognin (Ubr1) and others $(40,46,47)$. However, one has to note that these experiments were performed using transfection of miR-H1 mimics and have not been confirmed in the context of virus infection. Similarly, the potential to regulate cellular transcriptional repressor Kelch-like 24 (KLHL24) has been shown for miR-H27 (48), another HSV-1 miRNA expressed at very low levels during the productive infection and not present in latency. The function of miR$\mathrm{H} 27$ remains puzzling, but it is possible that, by lowering the levels of the repressor, it can modulate the expression of immediate early genes to promote productive infection or initiate reactivation. The effects of ectopically expressed HSV-1 miRNA on cellular transcription and cell cycle progression have also been shown for HSV-1 miR-H4, and its HSV-2 homolog, which have been found to target cyclin-dependent kinase inhibitor $2 \mathrm{~A}(\mathrm{CDKN} 2 \mathrm{~A}, \mathrm{p} 16)$, a negative regulator of cell-cycle and PI3K/Akt pathway (49, 50). Having in mind that miR-H4 is relatively abundant in latency and that Akt signaling is vastly important for regulation of latency, the interplay between miR-H4 and this pathway might have a role in maintenance of latency (49). A few HSV-1 miRNAs have been found to potentially regulate different aspects of immunity, which is even more difficult to investigate due to non-conserved miRNA target sites (an example below) and reactivation techniques (e.g. mouse explanted ganglia) insensitive for discriminating the fine-tuning of gene expression. Nonetheless, Enk et al., have applied a functional screen to reveal potential HSV-1 miRNAs regulating the function of natural killer (NK) cells, and found that miR-H8 decreased the expression of several ligands for NK-activating receptors by targeting phosphatidylinositol glycan anchor biosynthesis class T (PIGT). PIGT is a member of the protein complex involved in the glycosylphosphatidylinositol (GPI) anchoring pathway, essential for the presentation of proteins on the cell surface (51). The exact importance of this possible regulation is unknown because the PIGT target sites are not conserved in mice, and thus very challenging to test in a relevant model. In addition to miR-H8 as a potential modulator of immunity, miR-H2 has been shown to target (DEAD)-box helicase 41 (DDX41), a cytosolic DNA sensor of the DNA-sensing pathway (52), but similarly, the biological relevance for the HSV-1 infection remains unknown.

\section{CONCLUSIONS}

The discovery of miRNAs expressed by HSV-1 and HSV-2 represented a paradigm shift in understanding the complex biology of these viruses. Although high hopes and lots of efforts have been put in investigations of miRNA roles in the regulation of latency, the results were somewhat frustrating. Viruses deficient for the expression of certain miRNAs, e.g. miR-H2, $-\mathrm{H} 3,-\mathrm{H} 4$ and -H1, -H6 did not show strong phenotypes, or were cell-, model- and virus-specific $(34,41,53)$. Was this unexpected? It has been shown that viruses with deletion of LAT promoter, which expresses barely detectable levels of most of the latency-associated miRNAs, efficiently establish latency and do not show strong reactivation phenotypes (26), indicating that latency is controlled by many different, some yet undefined, mechanisms, and that miRNAs are likely contributing to some extent. The currently used reactivation techniques (explanted ganglia) are very robust and not applicable to the analysis of finetuning of gene expression. On the other hand, productive HSV-1 infection is relatively short and inevitably leads to the destruction of the infected cells. Thus, one can ask questions like: Do miRNAs play any role in the regulation of genes in that phase of infection? There are several, yet weak, arguments to support the positive answer. First, a number of miRNAs have found to be associated with Ago (36) during the productive infection; second, some HSV-1 miRNAs, such as miR-H1, are expressed exclusively during the productive infection and not present in latency $(25,29)$; third, some late miRNAs have been found in exosomes; fourth, most of the research is based on the infected cells in culture, where infection might have different dynamics and outcomes; and fifth, the miRNA species specificity might play a strong role in these processes, as it has been shown for miR-H8 (51). Thus, the same questions remain unanswered. However, the fact that HSV-1 and HSV-2 (two closely related viruses) both encode miRNAs, including many positional homologs, strongly indicate that miRNAs play an important role for these viruses, but more effort and time is needed to reveal the exact molecular mechanism.

Acknowledgement: MPM and IJ have written the manuscript, and $A Z, N D$, JM have contributed in writing, generating the figure and valuable discussions. This work was supported by Croatian Science Foundation grant 8790 and the University of Rijeka Support grant to IJ.

\section{REFERENCES}

1. ROIZMAN B, KNIPE DM, WHITLEY RJ 2013 Fields virology. 6 ed. Philadelphia, PA: Lippincott Williams \& Wilkins.

2. JURAK I, GRIFFITHS A, COEN DM 2011 Mammalian alphaherpesvirus miRNAs. Biochim Biophys Acta-Gene Regul Mech 1809(11-12): 641-653.

https://doi.org/10.1016/j.bbagrm.2011.06.010

3. KENT JR, KANG W, MILLER CG, FRASER NW 2003 Herpes simplex virus latency-associated transcript gene function. J Neurovirol 9(3): 285-290. https://doi.org/10.1080/13550280390200994

4. GARBER DA, SCHAFFER PA, KNIPE DM 1997 A LAT-associated function reduces productive-cycle gene expression during 
acute infection of murine sensory neurons with herpes simplex virus type 1. J Virol 71(8): 5885-93.

5. PERNG GC, JONES C, CIACCI-ZANELLA J, STONE M, HENDERSON G, YUKHT A, SLANINA SM, HOFMAN FM, GHIASI H, NESBURN AB, WECHSLER SL 2000 Virus-induced neuronal apoptosis blocked by the herpes simplex virus latency-associated transcript. Science 287(5457): 1500-1503. https://doi.org/10.1126/science.287.5457.1500

6. THOMPSON RL, SAWTELL NM 2001 Herpes simplex virus type 1 latency-associated transcript gene promotes neuronal survival. J Virol 75(14): 6660-6675.

https://doi.org/10.1128/JVI.75.14.6660-6675.2001

7. CLIFFE AR, GARBER DA, KNIPE DM 2009 Transcription of the herpes simplex virus latency-associated transcript promotes the formation of facultative heterochromatin on lytic promoters. J Virol 83(16): 8182-90. https://doi.org/10.1128/JVI.00712-09

8. SRIVASTAVA R, DERVILLEZ X, KHAN AA, CHENTOUFI AA, CHILUKURI S, SHUKR N, FAZLI Y, ONG NN, AFIFI RE, OSORIO N, GEERTSEMA R, NESBURN AB., WECHSLER SL, BENMOHAMED L 2016 The herpes simplex virus latency-associated transcript gene is associated with a broader repertoire of virus-specific exhausted $\mathrm{CD} 8^{+} \mathrm{T}$ cells retained within the trigeminal ganglia of latently infected HLA transgenic rabbits. J Virol 90(8): 3913-28.

https://doi.org/10.1128/JVI.02450-15

9. DOLAN A, JAMIESON FE, CUNNINGHAM C, BARNETT BC, MCGEOCH DJ 1998 The genome sequence of herpes simplex virus type 2. J Virol 72(3): 2010-2021.

10. XU F, STERNBERG MR, KOTTIRI BJ, MCQUILLAN GM, LEE FK, NAHMIAS AJ, BERMAN SM, MARKOWITZ, LE 2006 Trends in herpes simplex virus type 1 and type 2 seroprevalence in the United States. JAMA 296(8):964-973. https://doi.org/10.1001/jama.296.8.964

11. FORWARD KR, LEE SH 2003 Predominance of herpes simplex virus type 1 from patients with genital herpes in Nova Scotia. Can J Infect Dis 14(2): 94-96. https://doi.org/10.1155/2003/168673

12. LOWHAGEN GB, TUNBACK P, ANDERSSON K, BERGSTROM T, JOHANNISSON G 2000 First episodes of genital herpes in a Swedish STD population: a study of epidemiology and transmission by the use of herpes simplex virus (HSV) typing and specific serology. Sex Transm Infect 76(3): 179-182. https://doi.org/10.1136/sti.76.3.179.

13. SUCATO G, WALD A, WAKABAYASHI E, VIEIRA J, COREY L 1998 Evidence of latency and reactivation of both herpes simplex virus (HSV)-1 and HSV-2 in the genital region. J Infect Dis 177(4): 1069-1072. https://doi.org/10.1086/515261

14. MARGOLIS TP, IMAI Y, YANG L, VALLAS V, KRAUSE PR 2007 Herpes simplex virus type 2 (HSV-2) establishes latent infection in a different population of ganglionic neurons than HSV-1: role of latency-associated transcripts. J Virol 81(4): 1872-1878. https://doi.org/10.1128/JVI.02110-06

15. BARTEL DP 2018 Metazoan microRNAs. Cell 173(1): 20-51. https://doi.org/10.1016/j.cell.2018.03.006

16. FRIEDMAN RC, FARH KK, BURGE CB, BARTEL DP 2009 Most mammalian mRNAs are conserved targets of microRNAs. Genome Res 19(1): 92-105. https://doi.org/10.1101/gr.082701.108

17. BARTEL DP 2004 MicroRNAs: genomics, biogenesis, mechanism, and function. Cell 116(2): 281-297. https://doi.org/10.1016/s0092-8674(04)00045-5

18. SHABALINA SA, KOONIN EV 2008 Origins and evolution of eukaryotic RNA interference. Trends Ecol Evol 23(10): 578-587. https://doi.org/10.1016/j.tree.2008.06.005

19. MASAKI T, AREND KC, LI Y, YAMANE D, MCGIVERN DR, KATO T, WAKITA T, MOORMAN NJ, LEMON SM 2015 miR-122 stimulates hepatitis $C$ virus RNA synthesis by altering the balance of viral RNAs engaged in replication versus translation. Cell Host Microbe 17(2): 217-228.

https://doi.org/10.1016/j.chom.2014.12.014

20. GOTTWEIN E, CULLEN BR 2008 Viral and cellular microRNAs as determinants of viral pathogenesis and immunity. Cell Host Microbe 3(6): 375-387.

https://doi.org/10.1016/j.chom.2008.05.002

21. RUTKOWSKI AJ, ERHARD F, L'HERNAULT A, BONFERT T, SCHILHABEL M, CRUMP C, PHILIP ROSENSTIEL, EFSTATHIOU S, ZIMMER R, FRIEDEL CC, DÖLKEN L 2015 Widespread disruption of host transcription termination in HSV1 infection. Nat Commun 6: 7126.

https://doi.org/10.1038/ncomms8126

22. BOLDOGKOI Z, SZUCS A, BALAZS Z, SHARON D, SNYDER M, TOMBACZ D 2018 Transcriptomic study of Herpes simplex virus type-1 using full-length sequencing techniques. Sci Data 5: 180266. https://doi.org/10.1038/sdata.2018.266

23. TOMBACZ D, MOLDOVAN N, BALAZS Z, GULYAS G, CSABAI Z, BOLDOGKOI M, SNYDER M, BOLDOGKÖI Z 2019 Multiple long-read sequencing survey of herpes simplex virus dynamic transcriptome. Front Genet. 10: 834. https://doi.org/10.3389/fgene.2019.00834

24. COKARIC BRDOVCAK M, ZUBKOVIC A, JURAK I 2018 Herpes simplex virus 1 deregulation of host microRNAs. Noncoding RNA 4(4), 36 https://doi.org/10.3390/ncrna4040036

25. JURAK I, KRAMER MF, MELLOR JC, VAN LINT AL, ROTH FP, KNIPE DM, Coen DM 2010 Numerous conserved and divergent microRNAs expressed by herpes simplex viruses 1 and 2. J Virol 84(9): 4659-4672. https://doi.org/10.1128/JVI.02725-09.

26. KRAMER MF, JURAK I, PESOLA JM, BOISSEL S, KNIPE DM, COEN DM 2011 Herpes simplex virus 1 microRNAs expressed abundantly during latent infection are not essential for latency in mouse trigeminal ganglia. Virology 417(2): 239-247. https://doi.org/10.1016/j.virol.2011.06.027

27. ZHU J, KANG W, MARQUART ME, HILL JM, ZHENG X, BLOCK TM, FRASER NW 1999 Identification of a novel 0.7-kb polyadenylated transcript in the LAT promoter region of HSV-1 that is strain specific and may contribute to virulence. Virology 265(2): 296-307. https://doi.org/10.1006/viro.1999.0057

28. PAN D, LI G, MORRIS-LOVE J, QI S, FENG L, MERTENS ME, JURAK I, KNIPE DM, COEN DM 2019 Herpes simplex virus 1 lytic infection blocks microRNA (miRNA) biogenesis at the stage of nuclear export of pre-miRNAs. MBio 10(1). https://doi.org/10.1128/mBio.02856-18

29. COKARIC BRDOVCAK M, ZUBKOVIC A, FERENCIC A, SOSA I, STEMBERGA V, CUCULIC D, ROKIĆ F, VUGREK O, HACKENBERG M, JURAK I 2018 Herpes simplex virus 1 miRNA sequence variations in latently infected human trigeminal ganglia. Virus Res 256: 90-95.

https://doi.org/10.1016/j.virusres.2018.08.002

30. KALAMVOKI M, DU T, ROIZMAN B 2014 Cells infected with herpes simplex virus 1 export to uninfected cells exosomes containing STING, viral mRNAs, and microRNAs. Proc Natl Acad Sci USA 111(46): E4991-4996. https://doi.org/10.1073/pnas.1419338111

31. HUANG RQ, WU JM, ZHOU XS, JIANG HF, ZHOU GG, ROIZMAN B 2019 Herpes simplex virus 1 microRNA miR-H28 exported to uninfected cells in exosomes restricts cell-to-cell virus spread by inducing gamma interferon mRNA. J Virol 93(21): e01005-19. https://doi.org/10.1128/JVI.01005-19

32. WANG L, CHEN XQ, ZHOU XS, ROIZMAN B, ZHOU GG 2018 miRNAs targeting ICP4 and delivered to susceptible cells in exosomes block HSV-1 replication in a dose-dependent manner. Mol Ther 26(4): 1032-1039.

https://doi.org/10.1016/j.ymthe.2018.02.016 
33. VAN ROOIJ E 2011 The art of microRNA research. Circ Res 108(2): 219-234.

https://doi.org/10.1161/CIRCRESAHA.110.227496

34. PAN D, PESOLA JM, LI G, MCCARRON S, COEN DM 2017 Mutations inactivating herpes simplex virus 1 microRNA miR-H2 do not detectably increase ICP0 gene expression in infected cultured cells or mouse trigeminal ganglia. J Virol 91(2): e02001-16. https://doi.org/10.1128/JVI.02001-16

35. UMBACH JL, KRAMER MF, JURAK I, KARNOWSKI HW, COEN DM, CULLEN BR 2008 MicroRNAs expressed by herpes simplex virus 1 during latent infection regulate viral mRNAs. Nature 454(7205): 780-783. https://doi.org/10.1038/nature07103

36. FLORES O, NAKAYAMA $S$, WHISNANT AW, JAVANBAKHT H, CULLEN BR, BLOOM DC 2013 Mutational inactivation of herpes simplex virus 1 microRNAs identifies viral mRNA targets and reveals phenotypic effects in culture. J Virol 87(12): 6589-6603. https://doi.org/10.1128/JVI.00504-13

37. JIANG X, BROWN D, OSORIO N, HSIANG C, BENMOHAMED L, WECHSLER SL 2016 Increased neurovirulence and reactivation of the herpes simplex virus type 1 latency-associated transcript (LAT)-negative mutant dLAT2903 with a disrupted LAT miR-H2. J Neurovirol 22(1): 38-49.

https://doi.org/10.1007/s13365-015-0362-y

38. KAWAMURA Y, BOSCH-MARCE M, TANG S, PATEL A, KRAUSE PR 2018 Herpes simplex virus 2 latency-associated transcript (LAT) region mutations do not identify a role for LAT-associated microRNAs in viral reactivation in guinea pig genital models. J Virol 92(14): e00642-18. https://doi.org/10.1128/JVI.00642-18

39. PAN D, FLORES O, UMBACH JL, PESOLA JM, BENTLEY P, ROSATO PC, LEIB DA, CULLEN BR, COEN DM 2014 A neuron-specific host microRNA targets herpes simplex virus-1 ICP0 expression and promotes latency. Cell Host Microbe 15(4): 446-456. https://doi.org/10.1016/j.chom.2014.03.004

40. DUAN F, LIAO J, HUANG Q, NIE Y, WU K 2012 HSV-1 miRH6 inhibits HSV-1 replication and IL-6 expression in human corneal epithelial cells in vitro. Clin Dev Immunol 2012: 192791. https://doi.org/10.1155/2012/192791

41. BARROZO ER, NAKAYAMA S, SINGH P, NEUMANN DM, BLOOM DC 2020 Deletion of herpes simplex virus 1 microRNAs miR-H1 and miR-H6 impairs reactivation. J Virol https://doi.org/10.1128/JVI.00639-20

42. HILL JM, GARZA HH JR, SU YH, MEEGALLA R, HANNA LA, LOUTSCH JM, THOMPSON HW, VARNELL ED, BLOOM DC, BLOCK TM 1997 A 437-base-pair deletion at the beginning of the latency-associated transcript promoter significantly reduced adrenergically induced herpes simplex virus type 1 ocular reactivation in latently infected rabbits. J Virol 71(9): 65556559.

43. CHAN D, COHEN J, NAITO J, MOTT KR, OSORIO N, JIN L, FRASER NW, JONES C, WECHSLER SL, PERNG GC 2006
A mutant deleted for most of the herpes simplex virus type 1 (HSV1) UOL gene does not affect the spontaneous reactivation phenotype in rabbits. J Neurovirol 12(1): 5-16.

https://doi.org/10.1080/13550280500516401

44. LAI EC, WIEL C, RUBIN GM 2004 Complementary miRNA pairs suggest a regulatory role for miRNA:miRNA duplexes. RNA 10(2): 171-175. https://doi.org/10.1261/rna.5191904

45. JURAK I, SILVERSTEIN LB, SHARMA M, COEN DM 2012 Herpes simplex virus is equipped with RNA- and protein-based mechanisms to repress expression of ATRX, an effector of intrinsic immunity. J Virol 86(18): 10093-10102. https://doi.org/10.1128/JVI.00930-12

46. ZHENG K, LIU Q, WANG S, REN Z, KITAZATO K, YANG D, WANG Y 2018 HSV-1-encoded microRNA miR-H1 targets Ubrl to promote accumulation of neurodegeneration-associated protein. Virus Genes 54(3): 343-350. https://doi.org/10.1007/s11262-018-1551-6

47. NAQVI AR, SHANGO J, SEAL A, SHUKLA D, NARES S 2018 Viral miRNAs alter host cell miRNA profiles and modulate innate immune responses. Front Immunol 9: 433. https://doi.org/10.3389/fimmu.2018.00433

48. WU W, GUO Z, ZHANG X, GUO L, LIU L, LIAO Y, WANG J, WANG L, LI Q 2013 A microRNA encoded by HSV-1 inhibits a cellular transcriptional repressor of viral immediate early and early genes. Sci China Life Sci 56(4): 373-383. https://doi.org/10.1007/s11427-013-4458-4

49. ZHAO H, ZHANG C, HOU G, SONG J 2015 MicroRNA-H4$5 p$ encoded by HSV-1 latency-associated transcript promotes cell proliferation, invasion and cell cycle progression via p16-mediated PI3K-Akt signaling pathway in SHSY5Y cells. Int J Clin Exp Med 8(5): 7526-7534.

50. ZHAO Y, YANG J, LIU Y, FAN J, YANG H 2019 HSV-2-encoded miRNA-H4 regulates cell cycle progression and Act-D-induced apoptosis in HeLa cells by targeting CDKL2 and CDKN2A. Virol Sin 34(3): 278-286. https://doi.org/10.1007/s12250-019-00101-8.

51. ENK J, LEVI A, WEISBLUM Y, YAMIN R, CHARPAK-AMIKAM Y, WOLF DG, MANDELBOIM O 2016 HSV1 microRNA modulation of GPI anchoring and downstream immune evasion. Cell Rep 17(4): 949-956.

https://doi.org/10.1016/j.celrep.2016.09.077

52. DUAN Y, ZENG J, FAN S, LIAO Y, FENG M, WANG L, Zhang Y, Li Q 2019 Herpes simplex virus type 1-encoded miR-H2-3p manipulates cytosolic DNA-stimulated antiviral innate immune response by targeting DDX41. Viruses 11(8): 756 https://doi.org/10.3390/v11080756

53. JIANG X, BROWN D, OSORIO N, HSIANG C, LI L, CHAN L, BENMOHAMED L, WECHSLER SL 2015 A herpes simplex virus type 1 mutant disrupted for microRNA H2 with increased neurovirulence and rate of reactivation. J Neurovirol 21(2): 199209. https://doi.org/10.1007/s13365-015-0319-1. 